\title{
Statistics 101
}

\section{Statistics for Medical Writers and Editors: An Essential Skills Workshop of the American Medical Writers Association Bart J. Harvey, Editor}

American Medical Writers Association; 2012

$\mathrm{S}$ tudents of statistics come in many forms, from nervous initiates in dim lecture halls tackling for the first time the intricacies of sample distribution, to advanced practitioners pushing the theoretical boundaries of the field. What they all have in common is a recognition of the practical use of these dark arts in their lives, ranging from data interpretation to study design, even to selecting barley to produce a perfect pint of "the black stuff." In this slim volume, Harvey and colleagues present a cogent introduction to key concepts in statistics, the understanding of which will form a solid foundation for writers coming across statistics for the first time.

This book comprises a core module of the American Medical Writers' Association's "Essential Skills" certificate course, a professional development program for biomedical writers and editors. While many in this field will

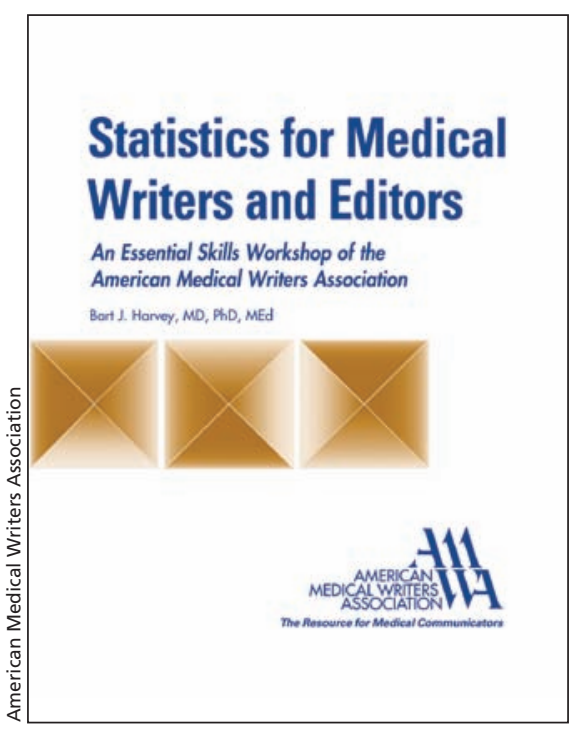

chapter. Key concepts and learning objectives are clearly highlighted. Each chapter is followed by self-assessment questions, which culminate in a multiple-choice test that can be submitted for course credit.

I found the writing style clear. The authors, particularly in their treatment of frequentist inference and the $p$ value, are adept at explaining statistical terminology that is often confusing or paradoxical to the ingénue. Figures are intu-

\section{A firm conceptual foundation for manuscript review and data interpretation}

have a background in science, approximately one-third come from English literature or humanities backgrounds. ${ }^{2}$ Consequently, this book is designed to provide an introduction to basic statistical concepts for candidates entirely new to the field, within a study time of 2-5 hours.

Four chapters illuminate data types, central tendency, measures of variability and, finally, hypothesis testing and frequentist inference. A lot of thought has gone into the structure of each itive and add to the text. The authors concentrate on statistical concepts, rather than extensive numeracy. Indeed, this lucid book might not only be useful to the statistics beginner, it may also be an invaluable tool for the often tonguetied lecturer who draws the short straw for Statistics 101.

The book comes with a supplementary CD (PC only), which contains a copy of the textbook. Here, however, the opportunity to present the material in a more interactive or multimedia manner that might suit other learning styles has been lost, and might be considered for a future edition.

In comparing clinical and statistical significance, the authors acknowledge that inappropriate presentation or interpretation of data can be used to hide a multitude of sins. These commonly include using error bars to describe technical replicates or conflating correlation and causation. A figure can not only paint a thousand words, but also add meaning to data that might necessarily be lost in the text. Even though medical editors and writers will usually have access to statisticians, common pitfalls in the presentation of data are something that the authors might consider for a future edition.

Harvey and colleagues have produced a textbook that highlights key concepts in statistics in a non-numerical, yet intelligible manner. Designed as a basic introduction for non-medical beginners, it provides a firm conceptual foundation for manuscript review and data interpretation. Its wellordered and lucid style provides tips that teachers of Statistics 101 would do well to emulate.

\section{James B. Canavan MB BCh MRCPI \\ Department of Experimental \\ Immunobiology and the \\ MRC Centre for Transplantation \\ King's College London \\ London, UK}

\section{References}

1. The probable error of a mean. Biometrika 1908;6: $1-25$.

2. Hudson S, Vivirito M. Results of the 2008 membership survey. AMWA 2008;23:198-200.

Acknowledgements: This work was supported by a doctoral research fellowship from the National Institute for Health Research and also by the UK Department of Health via the NIHR comprehensive Biomedical Research Centre award to Guy's \& St Thomas' NHS Foundation Trust and King's College London.

CMAJ 2013. DOI:10.1503/cmaj.121328 